\title{
Advanced management and monitoring functions at the TMA 550AL manufacturing centre, used for ATR
}

\author{
Moldovan Ovidiu PhD \\ University of Oradea, Faculty of \\ IMT, Department of Mechatronics, \\ Oradea, Romania \\ ovidiu30@gmail.com
}

\author{
Moga Ioan PhD \\ University of Oradea, Faculty of \\ IMT, Department of Mechatronics, \\ Oradea, Romania \\ imoga@uoradea.ro
}

\author{
Géza Husi PhD \\ University of Debrecen, Faculty of \\ Engineering, \\ Dpt. of Electrical Engineering and \\ Mechatronics Debrecen, Hungary \\ husigeza@eng.unideb.hu
}

\begin{abstract}
This paper amiss to make an overview of the management and monitoring functions implemented at the TMA $550 \mathrm{AL}$ flexible manufacturing system, functions that are used to implement the automatic tool readjustment function
\end{abstract}

Keywords-flexible cells, tool management functions, tool monitoring function, motor load monitoring.

\section{INTRODUCTION}

The automatic tool readjustment function is abbreviated ATR. This function is specific the Flexible Manufacturing Cell levels and Flexible Manufacturing System level and is task is to prepare a new set of tools in the storage system of the machine for the next item to be manufactured while the current item is being manufactured [1].

From the point of view of the equipment needed to perform the function ATC there is a great variety of solutions according to realization of ATR function. The usual solutions depend on the type of ATC and is based on the level of machine used.

The TMA 55AL (Fig. 1) has been upgraded to include an ATR function. The solution used is based on a tool storage unit accessible to the tool changer of the work centre.

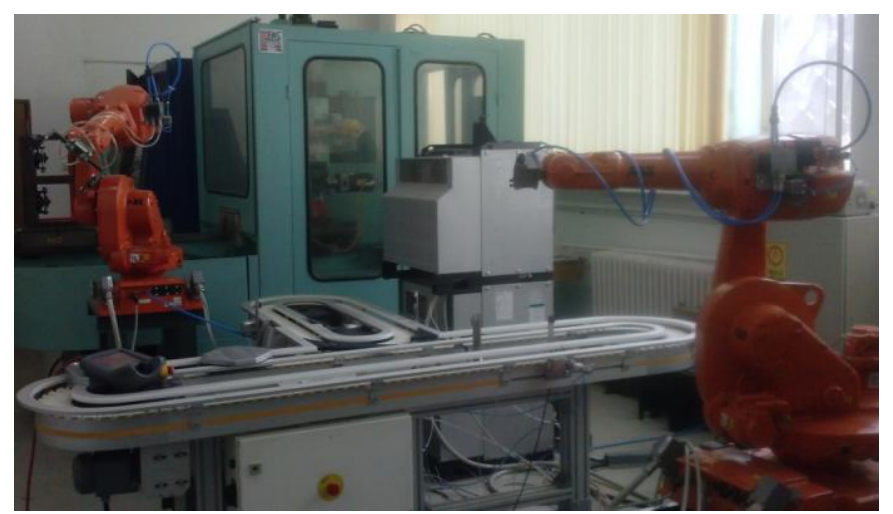

Fig 1. The TMA $55 \mathrm{Al}$ flexible manufacturing cell
The tool storage unit accessible to the ATC is loaded in the machine using the systems APC function, and is based on a tombstone device.

The steps necessary to implement the ATR function are:

- Determining the list of necessary tools for the next piece to be manufactured.

- Making the equipment and devices necessary to implement

- Making and integrating the specific software necessary for the ATR function

\section{THE TOOL SELECTION}

The ATR function must realize the physical transfer of the tools between the central storage unit and the ATC storage and also make the necessary upgrade in the tool lists (ATC tool list and in the list of tools available at FMS level).

In order to be able to operate changes in the tool list of the ATC which is managed by the Fanuc software on the $310 \mathrm{i}$ $\mathrm{CNC}$ the codification of the tools and all other information that are necessary to be "delivered" with the tool must be known.

Fanuc 310i CNC equipment machine allows the tool selection by calling the $\mathrm{T}$ address. The form of tool address can be set so that it includes information on the number of the tool and the position for the offset for each tool in the offset table. The permitted alternatives are presented in table 1 .

TABLE I. T CODE STRUCTURE ALLOWED BY THE CNC[2]

\begin{tabular}{|l|l|}
\hline T code & T code structure \\
\hline $\mathrm{T}_{------}-$ & $\begin{array}{l}\text { First 7 bytes indicate the tool } \\
\text { number; the last digit indicates the } \\
\text { number of the tool's offset. }\end{array}$ \\
\hline
\end{tabular}




\begin{tabular}{|c|c|c|}
\hline $\begin{array}{l}\mathrm{T}_{-----} \\
-\end{array}$ & - & $\begin{array}{l}\text { First } 6 \text { bytes indicate the tool } \\
\text { number, the last digits indicates the } \\
\text { number of the tool's offset. }\end{array}$ \\
\hline $\begin{array}{l}\mathrm{T}_{-----} \\
--\end{array}$ & - & $\begin{array}{l}\text { First } 5 \text { bytes indicate the tool } \\
\text { number, the last digits indicates the } \\
\text { number of the tool's offset. }\end{array}$ \\
\hline
\end{tabular}

The maximum number of bytes of address for $\mathrm{T}$ tools identifiers managed by the equipment can be set using parameters (between 1 and 8 bytes). There is the possibility of automatically setting the number bytes according to the available tool offsets. Thus, in the case where the number of offset positions is between 1 and 9 will have seven bytes for the $\mathrm{T}$ addresses, where if the number of offset addresses is from 10-99 $\mathrm{T}$ address will have 6 bytes and if the number of positions of the offset-s is between 100 to 999 the number of bytes of address $\mathrm{T}$ will be 5 .

Given the maximum number of tools that can be stored in the ATC we have opted for a T code with 2 byte without including of the offset. The TMA 55AL machining centre using as addresses in form of TXX between T01 and T99. The Fanuc equipment can use the T00 address, but this is not present in the tool list, the T00 address is reserved for the tool in the spindle.

Tool management function manages the information regarding tools, including information about the tool offset that lifetime of existing tools in the ATC. The ATR function must upgrade this information in order to ensure the optimal use of the tools.

Identical tools available in the ATC magazine can be grouped into groups of tools. For each tool is stored a number of parameters such as tool number, permitted time of use, status (e.g. tool breakage conditions), the characteristics of the tool compensation (H-length, D-diameter, $\mathrm{W}$-wear), maximum spindle speed for each tool.

These data are generically called tool management data.

When a tool number is invoked using a code such as T01, the $\mathrm{CNC}$ will look for a tool in the same group that has the lowest usage time.

Tool management data stored using these functions are [2]:

- Number of tool, T code, data length 4 bytes;

- The counter for the lifetime of tool and the number of uses, 4 bytes data length, values allowed for the life of up to $3,599,999$ and 0 (999 hours 59 minutes 59 seconds);

- The maximum use of tools, data length 4 bytes, the maximum value allowed for use 0 to 3,599,999 s (999 hours 59 minutes 59 seconds).

- Tool status, data length one byte, possible values: 0management function is not active tool, 1 tool was not used, the remaining service life 2, 3 service life used, 4 broken tool.

\section{ATC FUNCTION}

The ATC function stores the tools in a storage unit (Fig. 2) and also changes the tool in the spindle with the requested tool from the magazine using a hydraulic manipulator (Fig 3).

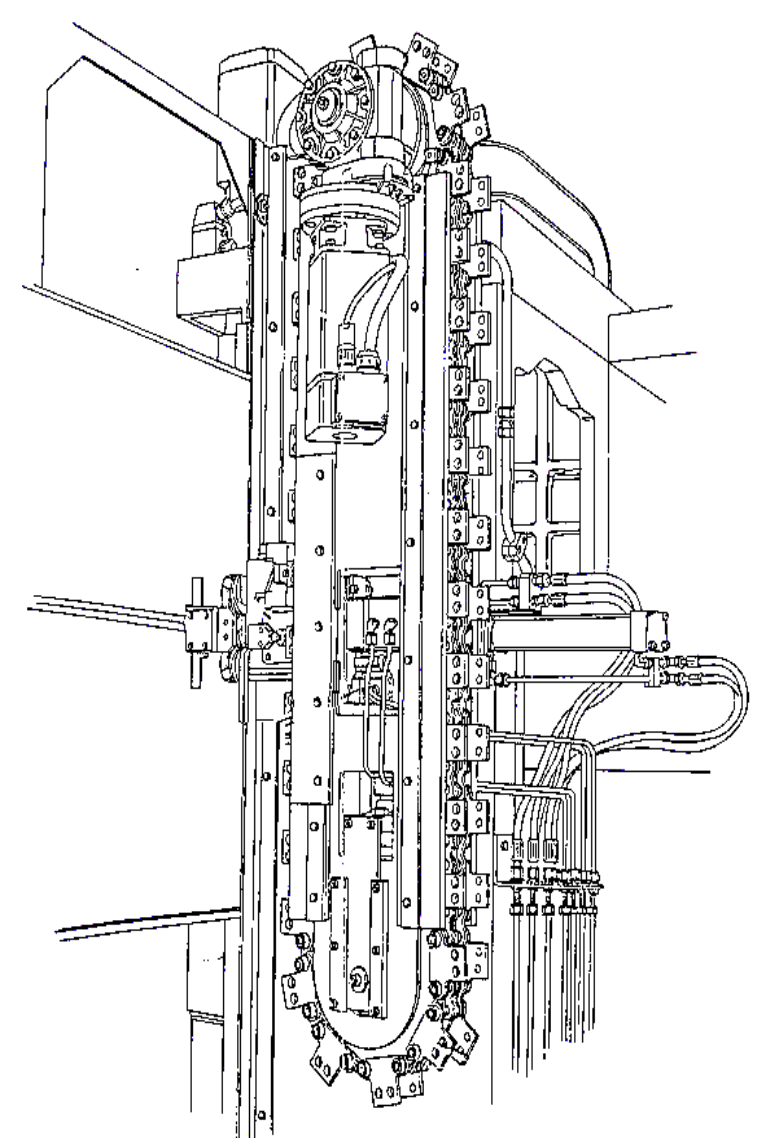

Fig 2. Tool storage unit for the machining centre [3]

At the TMA 55 AL the ATR function is realized by using the ATC function for the transfer of the tools from the storage unit to the ATC storage.

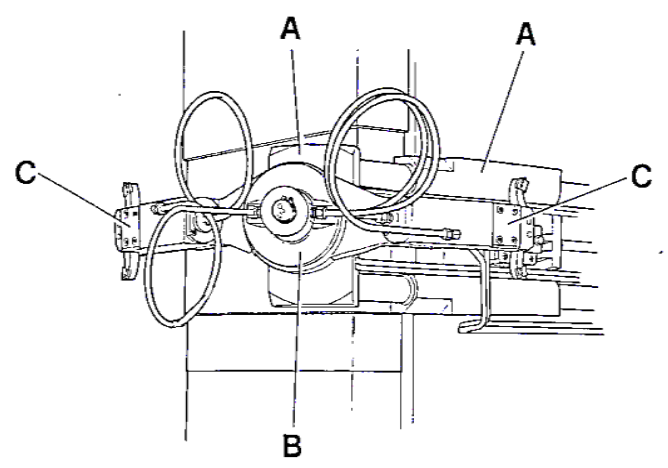

Fig 2. Hydraulic ATC manipulator of the machining centre [3] 


\begin{tabular}{|l|c|c|}
\hline \multicolumn{1}{|c|}{ Name } & Begin date & End date \\
\hline Movement of $Y$ axis to the tool changing position & $1 / 1 / 14$ & $1 / 2 / 14$ \\
\hline Orientation of the main spindle & $1 / 2 / 14$ & $1 / 3 / 14$ \\
\hline Tool storage positioning & $1 / 3 / 14$ & $1 / 7 / 14$ \\
\hline Closing of prehension device & $1 / 7 / 14$ & $1 / 8 / 14$ \\
\hline Unloking of tool for main spindle & $1 / 8 / 14$ & $1 / 9 / 14$ \\
\hline Extraction of tool form main spinlde & $1 / 9 / 14$ & $1 / 10 / 14$ \\
\hline 180 dgr rotation & $1 / 10 / 14$ & $1 / 11 / 14$ \\
\hline Tool replacement & $1 / 11 / 14$ & $1 / 12 / 14$ \\
\hline Locking the new tool & $1 / 12 / 14$ & $1 / 13 / 14$ \\
\hline Unloking prehension device & $1 / 13 / 14$ & $1 / 14 / 14$ \\
\hline Movement of $Y$ axis in a programmed position & $1 / 14 / 14$ & $1 / 15 / 14$ \\
\hline
\end{tabular}

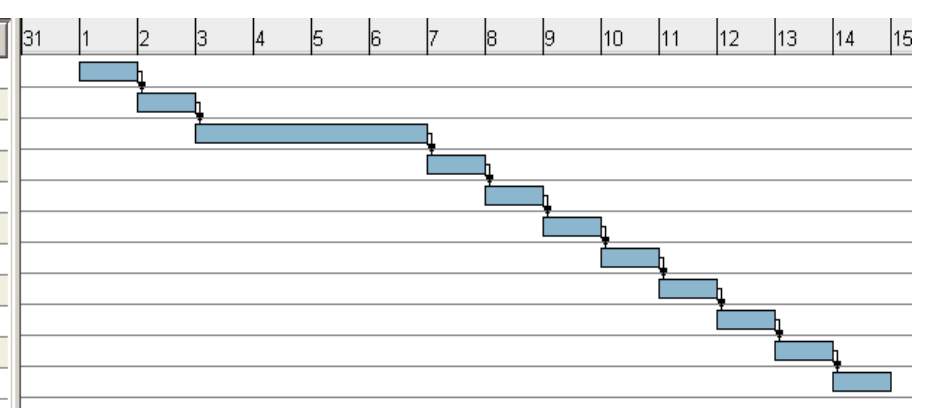

Fig. 3 Gantt chart of the ATC function at the flexible manufacturing centre in the TMA 55AL flexible manufacturing cell
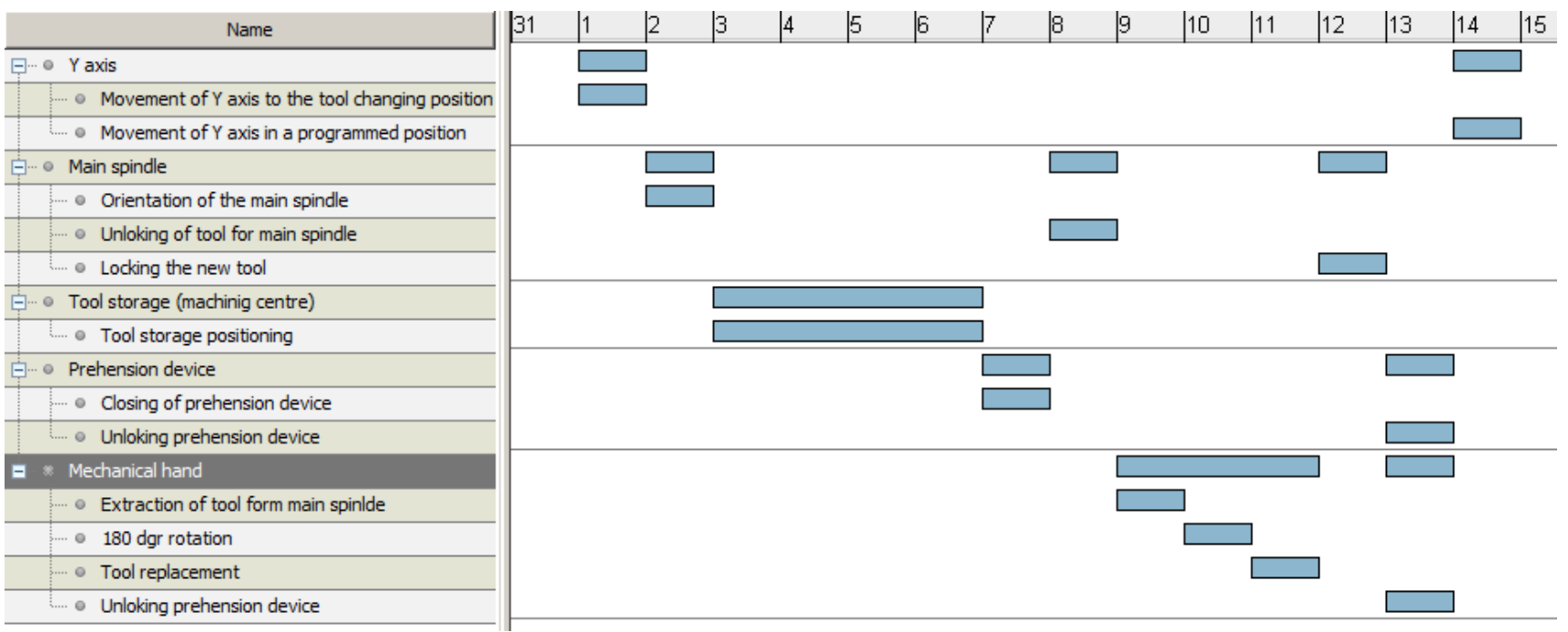

Fig. 4 Resource usage for the ATC function at the flexible manufacturing centre in the TMA 55AL flexible manufacturing cell

Fig. 3 presents the 3 Gantt chart of the ATC function at the flexible manufacturing centre in the TMA 55AL flexible manufacturing cell and in Fig. 4 is presented the resource usage for the ATC function at the flexible manufacturing centre

\section{FUNCTIONING PARAMETERS MONITORING SYSTEM AT THE FANUC 310 I CNC EQUIPMENT.}

The FANUC 310i CNC system has an integrated parameters monitoring function which among other options including the spindle motor parameters monitoring function.

Using this function a number of parameters related to the spindle motor can be measured that may contribute to the tools management and such be integrating the ATR function in a concept of tool management.

In figure 5 is shown the screen for monitor the parameters of the motor on the machine.

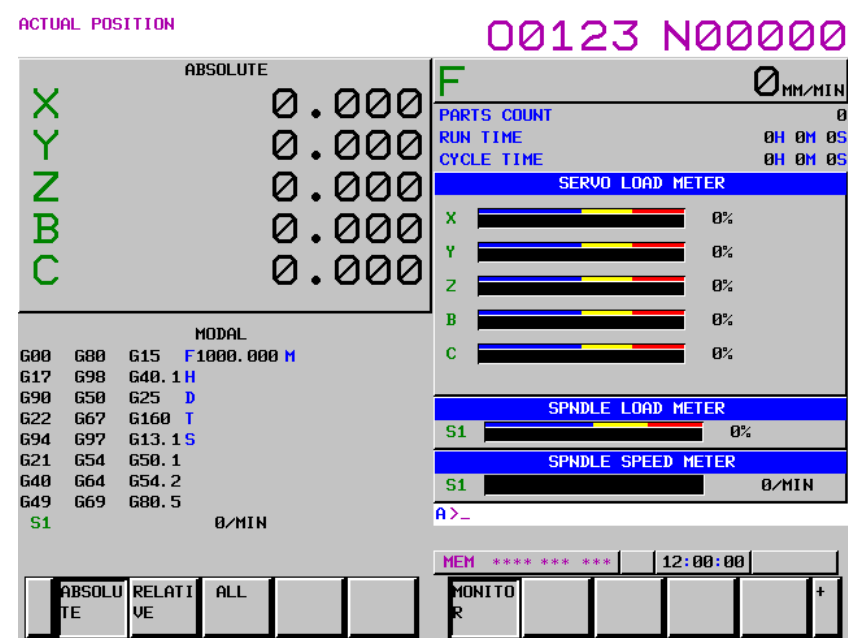

Fig. 5 Screen for monitor the parameters of the servo-motors (X,Y,Z, B and C axis and spindle motor) [4]

Using this function a data acquisition was realized for the parameters related to the spindle motor. In Fig. 6 is presented the menu for parameter settings of the data acquisition. 


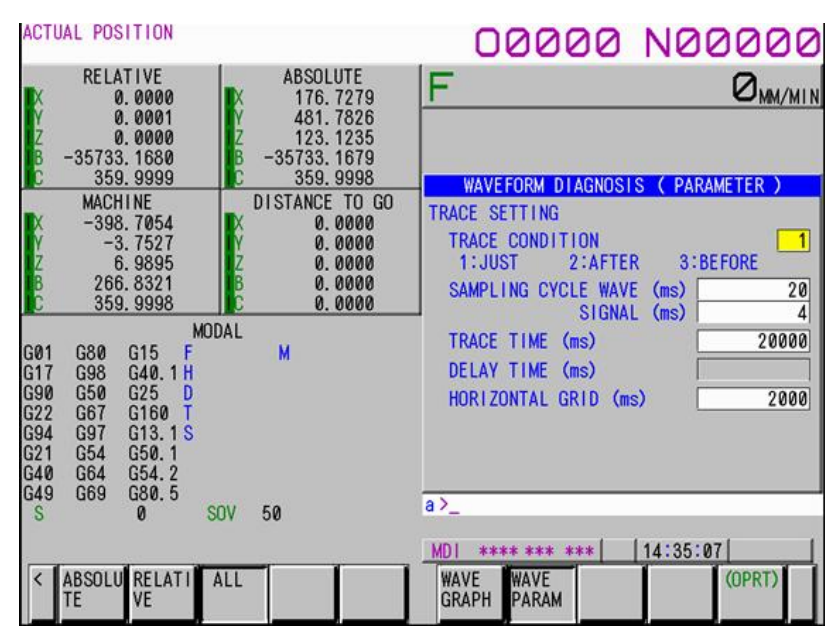

Fig. 6 Screen parameter settings (parameters to be acquired) and parameters of the DAQ

The data collected using the FANUC CNC was saved in a txt file using a structure specific to the equipment. The file was processed using Matlab to obtain the data for the spindle motor.

In table 2 are presented the values base values for the spindle load when with no work load.

TABLE II. BASE VALUES FOR THE SPINDLE LOAD WHEN WITH NO WORK LOAD

\begin{tabular}{|l|l|l|l|l|l|l|l|}
\hline 500 & 600 & 700 & 800 & 900 & 1000 & 1100 & 1200 \\
$\mathrm{rpm}$ & $\mathrm{rpm}$ & $\mathrm{rpm}$ & $\mathrm{rpm}$ & $\mathrm{rpm}$ & $\mathrm{rpm}$ & $\mathrm{rpm}$ & $\mathrm{rpm}$ \\
\hline $2 \%$ & $4 \%$ & $5 \%$ & $7 \%$ & $8 \%$ & $9 \%$ & $10 \%$ & $12 \%$ \\
\hline
\end{tabular}

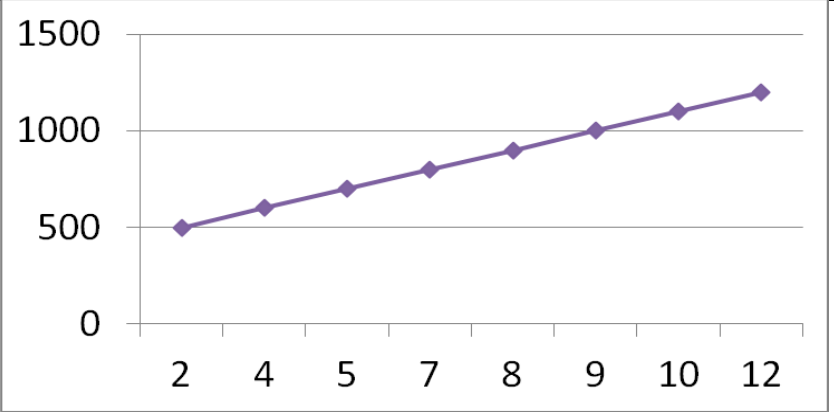

Fig. 7 Evolution of the spindle load (with no work load)[4]

Although these values are low, there use in monitoring the tool ware trough the monitoring of the tool ware is not feasible due to the transitory regime of the motor when the number of rotation is changed.

In order to highlight the transitory regime a series of test where realized using the same procedure, but the values of the motor load during the change of the rotation where acquired.

The transition from one speed to another involves loading the engine. The graph obtained for variations in speed from
$500 \mathrm{rpm}$ to $1100 \mathrm{rpm}$ with increments of $10 \%$ is shown in the figure 7 .

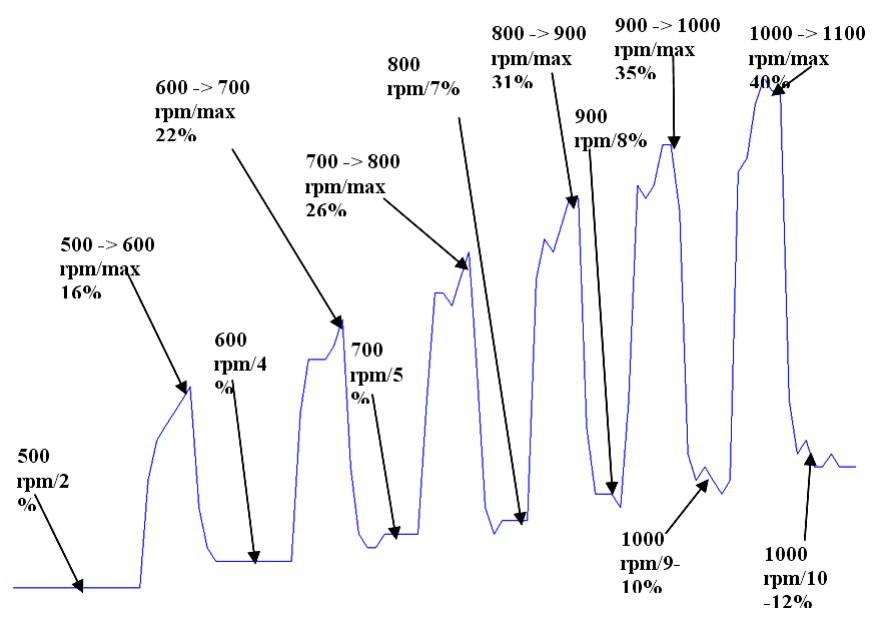

Fig. 7 The graph obtained for variations in speed from 500rpm to $1100 \mathrm{rpm}$ with increments of $10 \%[4]$

\section{CONCLUSION}

A new goal for the TMA 55Al is the integration of the ATR function with the tool management function, including the of activating the ATR based on data collected trough means of tool monitoring techniques. These techniques can offer information related to the tool ware. The most accessible information would be the data collected trough the waveform diagnosis function. In terms of workload monitoring the drive motor of the spindle is observed that at constant speeds workload is relatively small (max.12\%), however transitory regimes at speed change must be considered because the load can reach $40 \%$. In this context an algorithm to monitor engine load condition and monitoring tool spindle must take into account these transients. [4]

\section{Acknowledgment}

"This work was partially supported by the strategic grant POSDRU 107/1.5/S/77265, inside POSDRU Romania 20072013 co-financed by the European Social Fund - Investing in People."

\section{References}

[1] Macedon Ganea, Masini unelete si Echipamente tehnologice pentru prelucrarea pieselor prismatice.I- Module si echipamente specifice celulelor si sistemelor flexibile. Calitatea si receptia masinilor unelte CNC.: Editura Universității din Oradea, 2010.

[2] Fanuc, GE, Operation and maintenance handbook B-63947EN/01.

[3] TMA 55 manufacturing centre-User manual

[4] Ovidiu Moldovan, "Tool ware monitoring techniques and integration possibilities with the automatic tool readjustement function," Annals of the Oradea University Fascicle of Management and Technological Engineering, vol. XXII, no. 1, pp. 199-202, 2013. 